\title{
O COMPORTAMENTO ÉTICO DOS ENFERMEIROS DOS HOSPITAIS UNIVERSITÁRIOS
}

\author{
THE ETHICAL BEHAVIOUR OF THE NURSES OF THE UNIVERSITY HOSPITALS \\ EL COMPORTAMIENTO ÉTICO DE LOS ENFERMEROS DE LOS HOSPITALES \\ UNIVERSITARIOS
}

\author{
Raimunda Medeiros Germano ${ }^{2}$ \\ Rosineide Santana de Brito ${ }^{3}$ \\ Sheila Saint-Clair da S. Teodósio ${ }^{4}$
}

\begin{abstract}
RESUMO: Este trabalho teve como objetivos: - analisar a concepção da ética, presente no discurso e na prática dos enfermeiros; verificar a influência na formação dos estudantes de enfermagem e investigar sua contribuição para a compreensão da realidade moral e análise crítica da prática profissional. Na trajetória metodológica, privilegiou-se a análise qualitativa utilizando-se das técnicas de coleta de documentos, entrevistas coletivas e observações da prática cotidiana. Segundo a análise dos resultados, a concepção dos enfermeiros diz respeito à sua (in)satisfação no trabalho, à discriminação profissional e às questões corporativas da equipe de saúde. São incipientes as questões éticas relacionadas à competência técnica, ao respeito ao paciente enquanto ser social e aos direitos de cidadania dos usuários. Ocorre, ainda um distanciamento de uma compreensão da ética enquanto comportamento moral e uma visão crítica da profissão e đa assistência à saúde.
\end{abstract}

PALAVRAS-CHAVE: Ética - Ensino - Conduta ética da enfermagem

ABSTRACT: The aims of this study were to analyse the conception of ethics in the nurse's speech and practice, to verify its influence on nurses formation, and to investigate the nurses views regarding to the contribution of ethics to the comprehension of the moral reality and to the critical analysis of the nursing practice. The methodology focused on the qualitative analyses of data collected through the techniques of: document collection and analysis, group interviews, and observations of the nurses ethical behaviour during their practice. According to he results, the nurses conception of ethics relates insatisfaction to their work, to professional discrimination, and to corporate issues of health team. No reference was made to citizenship concerns. There is also a setting away from ethics understanding while moral behaviour and a critical view of the profession and of health care.

KEYWORDS: Ethics - Teaching - Nursing ethical behaviour

${ }^{1}$ Trabalho apresentado no $49^{\circ}$ CBEN-Belo Horizonte-M.G/1997

${ }^{2}$ Enfermeira, Doutora em Educaçăo, Prof ${ }^{2}$ Adjunta, UFRN.

${ }^{3}$ Enfermeira, Mestra e Doutoranda em Enfermagem, Prof ${ }^{\circ}$ Adjunta, UFRN.

${ }^{4}$ Enfermeira, Mestra e Doutoranda em Educação, Prof ${ }^{3}$ Adjunta, UFRN. 
RESUMEN: Este trabajo tuvo como objetivos: - analisar la concepción de la ética presente en el discurso y la práctica de los enfermeros; verificar la influencia en la formación de los estudiantes de enfermeria e investigar su contribución para la comprensión de la realidad moral y análisis crítica de la práctica profesional. En la trayectoria metodológica, se privilegió el análisis cualitativo utilizándose de las técnicas de colecta de documentos, entrevistas colectivas y observaciones de la práctica del día a día. Según el análisis de los resultados, la concepción de los enfermeros dice respecto a su (in)satisfacción en el trabajo, a la discriminación profesional y a las cuestiones corporativas del equipo de salud. Son incipientes las cuestiones éticas relacionadas a la competencia técnica, al respeto al paciente encuanto ser social y a los derechos de ciudadanía de los usuarios. Sucede, todavía, un distanciamento de una comprensión de la ética encuanto comportamiento moral y una visión crítica de la profesión y de la asistencia a la salud.

PALABRAS CLAVE: Ética - Enseñanza - Conducta ética de la enfermería.

"Toda ética é essencialmente social e política" (D.Pedro Casaldáliga)

\section{INTRODUÇÃO}

O presente trabalho se situa dentro de uma pesquisa mais ampla, cujo objeto de estudo constitui o comportamento ético da enfermagem, frente aos usuários dos hospitais da Universidade Federal do Rio Grande do Norte - UFRN. Aqui tratar-se-á tão somente os dados concernentes ao comportamento ético dos enfermeiros dos referidos hospitais. $O$ interesse por tal estudo foi despertado a partir, principalmente, de algumas pesquisas desenvolvidas sobre $o$ assunto na área da saúde, bem como das inúmeras denúncias e preocupaçōes no campo da ética, nas diferentes esferas da vida social brasileira. Dessa forma, sua pretensão foi efetuar uma análise com base no comportamento ético dos enfermeiros e demais membros da equipe de enfermagem na sua prática cotidiana, aprofundando a relação entre o que se teoriza no discurso acerca da ética e a realidade da prática profissional.

Por outro lado, a experiência do grupo de estudo, composto de enfermeiros docentes e assistenciais, que atuam nesses hospitais durante muitos anos, e professoras da disciplina de Ética e Exercício da Enfermagem, impulsionou não só uma reflexão acerca do papel das discussőes sobre a problemática estudada mas também exigiu uma maior contribuição no sentido de ampliar e aprofundar a apreensão dos principios éticos que norteiam a conduta dos profissionais de enfermagem no seu espaço de trabalho. 
Conforme Vazquez (1975: 16), "a ética tende a estudar certos tipos de fenômenos que se verificam realmente na vida do homem como ser social e constituem o que chamamos de mundo moral; ao mesmo tempo, procura estudá- los não deduzindo-os de princípios absolutos ou aprioritários, mas afundando suas raizes na própria existência histórica e social do homem"

Nesse sentido, interessa captar qual o entendimento do enfermeiro e demais membros da equipe de enfermagem sobre a realidade social, já que a ética deve fornecer a compreensão racional de um aspecto real, efetivo, do comportamento moral dos homens em sociedade. E dessa forma vale questionar: - a ética transmitida pelas escolas de enfermagem e pelos serviços de saúde, bem como as publicaçőes da área e ainda os diversos fóruns de debate da categoria sobre o assunto, têm contribuído para a compreensão da realidade moral, assim como para uma análise crítica da prática profissional? - ela tem concorrido para uma assistência mais humana aos pacientes e usuários dos serviços de saúde ou, ao contrário, se restringe a questões internas e corporativistas da profissão.

No que concerne à saúde, no Brasil, durante muitos anos esta foi visualizada, sobretudo, sob um prisma meramente tecnicista. A partir da década de 70 , com a contribuição das ciências sociais, é significativa a literatura crítica que vem sendo produzida e divulgada sobre o assunto, intrinsecamente relacionada aos aspectos sócio-econômicos, políticos e ideológicos de cada momento histórico específico. Apenas para citar parte desses autores, lembra-se: Donnangelo 1975,1976; Melo, 1977, 1983; Pessoa,- 1978; Landmann, 1983, 1985; Dallari, 1985; Merhy - 1985; Minayo - 1986; Teixeira - 1986, 1989; Fleury - 1984; Canesqui (org.) - 1995; Egry - 1996, cujas publicaçōes remetem a duas ordens de problemas: - a compreensão da saúde, do ponto de vista da determinação social, e análise crítica exercida sobre o Estado, no que diz respeito às políticas e às práticas de saúde por ele implementadas. Um aspecto, também salientado por essas obras, refere-se à formação essencialmente técnica dos profissionais de saúde, na qual a vinculação com a realidade social é praticamente escamoteada.

Com relação à produção teórica na área especifica da enfermagem, embora um pouco mais tardiamente, começam a despontar trabalhos que revelam a mesma ordem de preocupação e que, de certo modo, têm contribuido nas discussões sobre a formação e a prática de seus profissionais; são exemplos: Germano - 1984, 1993; Melo-1984; Silva-1986; Almeida- 1986; Rezende 1986; Nakamae -1987; Pires- 1989; Teodosio - 1990; Oliveira - 1990; Timoteo 1996; Vilar - 1997, entre outros. Por outro lado, vale esclarecer que essa vertente crítica, bem como os movimentos organizados da profissão, de orientação progressista, não se configuram como uma posição hegemônica no dominio da enfermagem.

Na verdade, o ensino de enfermagem, desde a sua criação no Brasil (1923), tem sido marcado por nuanças muito conservadoras e por um traço forte de submissão, conforme pode ser verificado em inúmeros de seus documentos. Vejamos o que expressa, por exemplo, o Juramento de Profissão de Fé das 
Enfermeiras Brasileiras da primeira turma da Escola Ana Neri, no ano de1925: "Comprometo-me solenemente a servir de todo o coração àqueles cujos cuidados me forem confiados. (...) Trabalharei sempre com fidelidade e obediência para com meus superiores e peço a Deus que me conceda paciência, benevolência $e$ compreensão, no santo mistério de cuidar dos que sofrem" (Pires, 1989: 136).

Da mesma forma, o ensino de ética, diferentemente de outras profissões de saúde, tem no sentimento de religiosidade um proeminente destaque; basta lembrar que, dentre as qualidades inerentes ao bom profissional, aparecem como caracteristicas de primeira ordem "a obediência, o respeito à hierarquia, a humildade, o espírito de servir, entre outros" (Germano, 1984:24).

Todavia, é importante destacar que, embora tenha sido sempre marcante a preocupação com a ética, no que toca à formação do enfermeiro, a orientação tem se pautado, conforme salientou-se antes, em urna direção por demais conservadora, fundamentada nos princípios da obediência e de forte sentimento de religiosidade. A título apenas de ilustração, no Congresso de 1952, realizado em São Paulo, quando se aprova o programa de Ética para o curso de enfermagem, recomenda-se: "deve basear-se na existência de Deus e da imortalidade da alma" (Turkiewicz, 1965). Dez anos mais tarde (1962), inspirada no tema Oficial do II Congresso Latino-Americano de Enfermagem, realizado no Rio de janeiro (1961) - " 0 sentido cristão de servir e a Enfermagem", a autora destaca: "viver para servir tem sido realçado como o lema do enfermeiro. No entanto, foi oportuno o tema escolhido pelo congresso pois o ideal de servir so será completo se for realizado dentro do espírito cristão" (Anacleto, 1926: 406).

Tal enfoque marca profundamente a enfermagem e passa a constituir objeto de crítica, até mesmo de outros profissionais. Tanto é assim que Landmann, em seu livro " Medicina não é Saúde", discorre em um dos seus capítulos sobre o tema " o enfermeiro e a ideologia da submissão" (Landmann, 1983: 171). A essa altura, cabe mencionar a existência de divergências, entre os enfermeiros, no que concerne à ética e ao seu ensino. Isto pode ser observado na proposta de reformulação do ensino de Ética (Alcântara, 1966:393), bem como em uma publicação posterior sobre nova abordagem do ensino de Ética Profissional, onde as autoras enfocam a necessidade de um ensino reflexivo que considere o exercício da enfermagem e seus aspectos éticos, dentro de uma visão histórica (Vieira e Oliva, 1985:192). No mesmo sentido, pesquisa realizada no ano de 1988, pelo professor de Ética da Escola de Enfermagem de Ribeirão Preto, Francisco de Assis Correia, dá conta da necessidade de uma reformulação total no ensino da Ética na enfermagem, tendo em vista o modelo predominantemente conservador ou tradicional em que se pauta o ensino dessa disciplina. Entretanto, deve ser ressaltado que essa postura, além de muito tímida, não se configura corno hegemônica no interior da enfermagem. 
A partir destas constatações, acompanhada evidentemente pela preocupação da não existência de estudos sobre o comportamento ético dos enfermeiros no exercício de sua prática profissional nos hospitais de ensino da UFRN, o presente trabalho teve como objetivos: - analisar a concepção da ética presente no discurso e na prática dos enfermeiros dos Hospitais Universitários do Rio Grande do Norte; verificar até que ponto o comportamento ético influencia na formação dos estudantes de enfermagem; e investigar em que medida a ética proclamada pelos enfermeiros contribui para a compreensão da realidade moral e para a análise crítica da prática profissional.

\section{TRAJETÓRIA METODOLÓGICA}

Para a viabilização da pesquisa, percorreu-se a trajetória metodológica da pesquisa qualitativa, utilizando-se da combinação das técnicas de coleta de documentos, observação participativa e entrevista com informantes qualificados. As fontes de pesquisa utilizadas foram revistas de enfermagem de grande circulação, revistas de outras áreas que tratam do terna de estudo, Anais dos Congressos de Enfermagem, Códigos de Ética, e trabalhos anteriores sobre a questão da ética, onde destacam-se aqueles produzidos por Vazquez, Germano, Gelain, Correia, Bauer, entre outros.

Utilizou-se, também, entrevistas coletivas com enfermeiros das unidades estudadas, sendo os depoimentos tratados qualitativamente, no decorrer do trabalho, numa tentativa de apreender-se a visão ética dos informantes, sua importância para a formação do enfermeiro e das suas relações com a realidade social. Constou, ainda, de observações feitas em enfermarias e ambulatórios dos hospitais universitários da Universidade Federal do Rio Grande; no desenvolvimento do estudo, são denominados de hospital $A, B, C, D$ e E. As observações ocorreram tanto nos ambulatórios, quanto nas unidades de internação, centro cirúrgico e recepção. Estas observações foram fundamentais para desmitificar as contradições entre os discursos proclamados nas entrevistas e a atuação prática dos enfermeiros nas relações com os usuários/pacientes.

A escolha dos hospitais de ensino se reveste de grande significação, não somente pelo vasto contingente de usuários atendidos diariamente mas sobretudo por constituirem urna instância educativa, na medida em que são utilizados como campo de prática, de uma parte considerável de alunos dos cursos da saúde, em particular, os de Enfermagem.

\section{A ÉTICA NO COTIDIANO DA ENFERMAGEM: REFLETINDO SOBRE SUA PRÁTICA}

Discutir a ética no cotidiano da enfermagem requer considerações acerca da expressão cotidianidade ou via cotidiana, pelo fato mesmo da dimensão que esta vem assumindo nos diversos campos do conhecimento e na própria produção. 
Agnes Heller (1989: 17) revela que "ninguém consegue identificar-se com sua atividade humano-genérica a ponto de poder desligar-se inteiramente da cotidianidade. E, ao contrário, não há nenhum homem, por mais "insubstancial" que seja, que viva tão somente na cotidianidade, embora essa o absorva preponderantemente".

Nessa perspectiva, o cotidiano é a vida de todos os dias e de todos os homens em qualquer época histórica que se possa analisar, embora em cada uma dessas épocas os ritmos e regularidades se distingam e, naturalmente, se tornam diferenciáveis. Se o cotidiano é a vida de todos os dias, com certeza está presente na familia, no trabalho, nas relações sociais, no lazer, enfim, em todas as esferas da vida do homem.

Ainda, no dizer de Heller, a vida cotidiana é a vida do homem inteiro; este participa com todos os aspectos de sua individualidade, de sua personalidade. "Nela, colocam-se em 'funcionamento' todos os seus sentidos, todas as suas capacidades intelectuais, suas habilidades manipulativas, seus sentimentos, paixões, idéias, ideologias".

Partindo dessa compreensão, como se situaria a questão ética no cotidiano de enfermagem dos hospitais universitários estudados? Na tentativa de debater tal questão, este estudo trabalhou as seguintes categorias de analise: significado da ética para os enfermeiros dessas instituições; a influência desta na formação dos enfermeiros; a relação entre a ética e a competência técnica; e, por fim, a prática profissional.

\section{O significado da ética na concepção dos enfermeiros}

Para os enfermeiros, participantes da pesquisa, a ética se identifica com: responsabilidade, competência, humanizaçăo, respeito ao próximo, busca da felicidade, normas e códigos, melhoria da qualidade individual, agir corretamente sempre e a relação do eu com os outros. Depreende-se, portanto, de suas falas um distanciamento do sentido de religiosidade que por muito tempo predominou no espirito da enfermagem. No entanto, ainda persiste uma concepção da ética codificada, onde normas e códigos são supervalorizados. Uma outra conotação que aparece, embora em minoria, mas merecedora de destaque, diz respeito à idéia da ética como "comportamento nato do profissional". Tal afirmação nega não somente a socialização do homem, mas, sobretudo, a importância do processo educativo.

\section{Influência da ética na formação dos enfermeiros}

A esse respeito os entrevistados ressaltam a responsabilidade do professor e do supervisor por representarem modelos para os alunos. Por outro lado, afirmam que a não integração existente entre a equipe multiprofissional interfere não somente na aprendizagem, mas influencia sobremaneira o comportamento profissional com os alunos. Nesse sentido, referem ainda que a existência de uma relação de desrespeito, desvalorização e autoritarismo entre os profissionais no espaço de trabalho se reflete negativamente na formação dos 
profissionais de saúde, e em particular do enfermeiro. Mencionam, da mesma forma, que a postura crítica, assumida cada vez mais pelos alunos, os forçam a uma atualização contínua para o melhor desempenho técnico profissional.

Assim, é importante ressaltar que está em curso, atualmente, um processo de renovação do ensino de ética, tendência ainda não hegemônica, mas que vem ampliando o seu raio de influência no âmbito da enfermagem. Nessa perspectiva, alguns programas contemplam objetivos extremamente avançados e se propõem a "refletir sobre os valores morais e a dialética da liberdade e da necessidade na formação do ato responsável". Enfim, existem programas que rompem com as visões unilaterais e se dispõem a abordar "as diferentes concepçôes que fundamentam o estudo da ética" e que pretendem "analisar a profissão de enfermagem como prática social nos diferentes momentos históricos".

\section{A ética e a competência}

A qualidade do desempenho profissional passa necessariamente pela questão da competência, cuja dimensão técnica e política muitas vezes aparece dicotomizada no discurso e na prática dos profissionais de enfermagem. A superação dessa dicotomia se dá exatamente através da dimensão ética que tem a propriedade de exercer a mediação entre ambas.

A esse respeito, a grande maioria, dos enfermeiros pesquisados, reconhece que essa competência decorre de um aprofundamento entre a escola e os hospitais; em outras palavras, entre o ensino e o serviço. Há também um consenso, por parte dos respondentes, no tocante à importância de um dominio técnico acerca das diversas áreas de especialização. Da mesma forma, esses profissionais afirmam não existir espírito de solidariedade na socialização e democratização por parte daqueles que detêm o saber.

Além disso, as entrevistas, ainda que de forma incipiente, salientam que o estimulo à produtividade vem interferindo na qualidade, concorrendo para uma assistência deficitária. No entanto, nas observações realizadas, verificou-se que na prática os enfermeiros não têm assumido a sua competência técnica nesta funçăo específica. Mesmo quando existe um número suficiente, desta categoria, as ações de maior complexidade, que segundo a Lei do Exercício Profissional são privativas do enfermeiro, são delegadas ao nível médio. Em todo período desta etapa da pesquisa, notou-se que estes profissionais, em sua maioria, têm se dedicado às ações burocráticas. Por exemplo, uma das enfermarias, onde ocorreram as observações, um paciente teve uma lipotimia e a enfermeira saiu correndo para chamar o médico, deixando a auxiliar atendendo a urgência, quando era da sua competência aquele atendimento. Muitas vezes a aproximação ao paciente ocorre apenas para fiscalizar a ação dos auxiliares e, quando observa falhas na ação executada, limitam-se a uma repreensão sem aproveitar o momento para ensiná-los a fazer corretamente. 
A competência, aqui aludida, encontra-se intrinsecamente relacionada ao compromisso ético. E, por essa razão, não é suficiente saber fazer e mesmo saber fazer bem, antes e acima de tudo é necessário querer. Não basta compreender a realidade e ter as ferramentas do saber fazer para que a transformação ocorra em direção ao projeto de saúde e da enfermagem que se deseja construir. É preciso querer, ter vontade política, a intencionalidade e a percepção do dever para que isso aconteça. Logo, esse ato compromissado, que naturalmente pressupöe uma interferência no real, contém, além dos elementos já mencionados, um outro aspecto que é a idéia de poder. Este encontra-se comumente relacionado à idéia de dominação e é representado, em certa medida, pelo saber. Portanto, se a associação saber e poder tem se prestado muito mais à dominação que à solidariedade na estrutura social em que vivemos, na saúde e, em particular, na enfermagem, representa um nó crítico no cotidiano profissional e um desafio à profissão. A existência, por exemplo de um grande contigente de pessoal não qualificado na equipe representa um problema básico e crucial para a qualidade da assistência de enfermagem prestada à população.

No entanto, essa realidade não garante necessariamente uma democratização do saber entre os membros da equipe; o mito da competência como sinônimo de apropriação desse saber, que também funciona dotado de poder, não é facilmente partilhado. Até certo ponto isso vem refletir o espírito de posse, o comportamento competitivo e individualista permeado pela moral egoista gerada no contexto do sistema capitalista. E é justamente em meio a essa situação conflituosa e contraditória, de inversão de valores, que a reflexão ética se faz cada vez mais necessária. Assim sendo, a qualidade em enfermagem passa pela competência técnica-ético-politica. Essa dimensões não são apenas referências conceituais, contribuem, de fato, para transformar o pensar e prática dos profissionais.

\section{CONSIDERAÇŎES FINAIS}

Após análise dos diferentes aspectos que conformam o comportamento ético dos enfermeiros, tomando como parâmetro entrevistas e observações realizadas junto a estes, nos hospitais Universitários da UFRN, constata-se que, embora a enfermagem tenha evoluido acerca do entendimento da ética, principalmente no tocante ao abandono do forte apelo à religiosidade, ainda predomina uma ética alienada à medida que exige de quem a pratica - sacrificio individual, obediência, submissão irrestrita a uma autoridade e a coerção externa. Os enfermeiros parecem ignorar, explicitamente, os seus direitos, as suas conquistas, os movimentos organizados através das associações de classe e se utilizam de um mecanismo de defesa, de desconhecimento da realidade deixando-se conduzir por um sentimento de passividade e resignação perante as autoridades ou chefes imediatos. 
Identifica-se, também, a concepção de uma ética utilitarista, pela referência "a satisfação do atendimento aos necessitados", muito mais como uma forma de prazer individual e cumprimento do dever do que como garantia e reconhecimento do direito social do paciente. No confronto dos dados, observase uma nítida contradição entre o discurso dos bons sentimentos expressos pelos informantes, corroborados pela ética codificada, e a intervenção prática desse enfermeiros.

Finalmente, pode-se inferir que o comportamento ético, dos enfermeiros pesquisados, distancia-se de uma ética que contribua para uma visão crítica da profissão e da assistência à saúde, o que certamente pode repercutir na formação dos estudantes de enfermagem que têm nos hospitais universitários um dos campos de prática.

\section{REFERÊNCIAS BIBLIOGRÁFICAS}

1. ALMEIDA, Maria Cecilia Puntel de \& ROCHA, Juan Stuardo Yazlle. $O$ saber de enfermagem e sua dimensão prática. São Paulo: Cortez, 1996.

2. AMORIM, Maria José Arléo B. "Enfermagem - profissão humanitária?" $R$. Bras. Enferm., Brasilia, v. 32, n. ${ }^{\circ}$, p. 359 - 68. out./dez. 1979.

3. BARKSTANOVSKI, V.. Ética. Traducido del ruso por Marisol Ciutat. Moscou: Processo, 1989.

4. BERNARDES, Antonieta Maria de. O programa de ética nas Escolas de Enfermagem. In: CONGRESSO NACIONAL DE ENFERMAGEM, 6, 1952, São Paulo. Anais.... São Paulo, Associação Brasileira de Enfermeiras Diplomadas, 1952.

5. BOCKWINKEL, Maria Rosalva. "Formação moral da enfermeira", R. Bras. Enferm., Rio de Janeiro, v.15, n. ${ }^{\circ}$ 6, p. 489 - 95, dez. 1962.

6. COCCO, Maria Inês Monteiro. A Ideologia do enfermeiro; prática educativa e saúde coletiva. Dissertação (Mestrado em Educação) Faculdade de Educação, Universidade de Campinas, 1991.

7. CORREIA, Francisco de Assis. As novas dimensões da ética médica na literatura dos últimos vinte e cinco anos (1960 - 1985) e suas implicações na reformulação do conteúdo do curso de ética em enfermagem. Ribeirão Preto, USP/Escola de Enfermagem, 1988 (Relatório de Pesquisa).

8. DURKHEIM, David Émile. L'Éducation Morale. Paris: F. Alcan, 1925.

9. EGRY, Emiko Yoshikawa. Saúde coletiva - construindo um novo método em enfermagem. São Paulo: İcone, 1996. 
10. FOUCAULT, Michel. Microfísica do poder. Tradução de Roberto Machado. Rio de Janeiro: Graal, 1979 (Biblioteca de Filosofia e História das Ciências, v.7).

11. O nascimento da clínica. Tradução de Roberto Machado. Rio de Janeiro: Forense,1977.

12. GERMANO, Raimunda Medeiros. Educaçäo e ideologia da enfermagem no Brasil. São Paulo: Cortez, História. Rio de Janeiro, Paz e Terra, 1989.

13. GERMANO, Raimunda Medeiros. A ética $e$ o ensino de ética na enfermagem do Brasil. São Paulo: Cortez, 1993.

14. HELLER, Agnes. O cotidiano e a história. Rio de Janeiro: Paz e Terra, 1989.

15. LANDMANN, Jayme. A ética médica sem máscara. Rio de Janeiro: Guanabara Dois, 1985.

16. MELO, Cristina Maria Meira de. Divisäo social do trabalho $e$ enfermagem. São Paulo: Cortez, 1986 (Serie Saúde e Sociedade).

17. NAKAMAE, Djair Daniel. Novos caminhos da enfermagem; por mudanças no ensino e na prática da profissão. São Paulo: Cortez, 1987.

18. NOBREGA, Silvia Maria. Enfermagem - a prática da profissão e a ideologia da submissão. Fortaleza. Dissertação (mestrado em educação), Universidade Federal do Ceará, 1991.

19. TEODOSIO, Sheila Saint-Clair da S.. A divisāo do trabalho e a cientificidade do saber sistematizado pela enfermagem: um caminho para o seu entendimento. Dissertação (mestrado em educação). CCSA/UFRN, Natal/RN, 1990.

20. TIMOTÉO, Rosalba pessoa de S.. O ensino da enfermagem moderna no Rio Grande do Norte. Dissertação (mestrado em educação) CCSA/ UFRN, Natal/RN,1997.

21. VAZQUEZ, Adolfo Sanchez. Ética. 2. ed., Tradução de João Dell'anna. Rio de Janeiro: Civilização Brasileira, 1975 (coleção Perspectivas do Homem, 46).

22. VILLAR, Rosana Lúcia A. de. Participação social em saúde: a experiência de Natal-RN. Dissertação (mestrado em Ciências Sociais). CCHLA/ UFRN, Natal / RN,1997. 